\title{
VALOR SISTEMATICO DE LA EPIDERMIS ABAXIAL DE LA LAMINA FOLIAR EN ESPECIES AMERICANAS DEL GENERO TRISETUM PERS. (POACEAE: POOIDEAE: AVENINAE)
}

\author{
SYSTEMATIC VALUE OF THE ABAXIAL LEAF-BLADE EPIDERMIS IN \\ AMERICAN SPECIES OF THE GENUS TRISETUM PERS. \\ (POACEAE: POOIDEAE: AVENINAE)
}

\author{
Víctor L. Finot \\ Departamento de Producción Animal, Facultad de Agronomía, Universidad de Concepción, Casilla 537,
} Chillán, Chile.vifinot@udec.cl

\section{RESUMEN}

Se estudió la epidermis abaxial de la lámina foliar en 29 especies y 3 variedades del género Trisetum s.s. Adicionalmente, se incluyó a Deschampsia brasiliensis (Louis-Marie) Valencia (= Trisetum brasiliense Louis-Marie), Helictotrichon bulbosum (Hitchc.) Parodi (= T. bulbosum Hitchc.) y Peyritschia deyeuxioides (Kunth) Finot (= T. deyeuxioides Kunth). Además, se realizaron observaciones de la epidermis adaxial en algunas especies sudamericanas, utilizando microscopio electrónico de barrido (MEB). Se confeccionó una matriz básica de datos (35 OTUs x 17 caracteres de la epidermis abaxial), a la que se aplicó análisis de agrupamientos (UPGMA) y análisis de componentes principales (ACP). Se reconoció cuatro grupos de especies: 1. Deschampsia brasiliensis. 2. Helictotrichon bulbosum. 3. Subg. Deschampsioideum (Louis-Marie) Finot (T. durangense Finot \& P.M.Peterson, T. filifolium Scribn. ex Beal, T. palmeri Hitchc., T. tonduzii Hitchc., T. viride (Kunth) Kunth y T. virletii E.Fourn.), T. pringlei (Scribn. ex Beal) Hitchc. y T. rosei Scribn. \& Merr. (Subg. Trisetum) . 4. Subg. Trisetum. Las secciones Trisetum y Trisaetera Asch. \& Graebn., no pueden distinguirse, así como no es posible distinguir Trisetum de Peyritschia E.Fourn. sobre la base de los caracteres estudiados.

Palabras claves: Anatomía foliar, Gramineae, análisis de agrupamientos, análisis de componentes principales.

\section{ABSTRACT}

The abaxial leaf epidermis of 29 species and 3 varieties of Trisetum s.s. was studied. In addition, Deschampsia brasiliensis (Louis-Marie) Valencia (= Trisetum brasiliense Louis-Marie), Helictotrichon bulbosum (Hitchc.) Parodi (= T. bulbosum Hitchc.) and Peyritschia deyeuxioides (Kunth) Finot $(=T$. deyeuxioides Kunth), were included. Observations of the adaxial epidermis of some South American species were made with scanning electron microscope (SEM). Cluster analysis (UPGMA) and principal component analysis (PCA) were applied to a basic data matrix (35 OTUs x 17 characters of abaxial epidermis). Four groups of species were recognized: 1. Deschampsia brasiliensis. 2. Helictotrichon bulbosum. 3. Subg. Deschampsioideum (Louis-Marie) Finot (T. durangense Finot \& P.M.Peterson, T. filifolium Scribn. ex Beal, $T$. palmeri Hitchc., T. tonduzii Hitchc., T. viride (Kunth) Kunth and T. virletii E.Fourn.), T. pringlei (Scribn. ex Beal) Hitchc. and T. rosei Scribn \& Merr. (Subg. Trisetum). 4. Subg. Trisetum. Sections Trisetum and Trisaetera Asch. \& Graebn., were not distinguished. On the basis of the studied characters the genera Trisetum and Peyritschia E.Fourn. were not recognized.

KEYwORDS: Leaf anatomy, Gramineae, cluster analysis, principal component analysis. 
Epidermis foliar de Trisetum (Poaceae): Finot, V.

\section{INTRODUCCION}

La utilidad taxonómica de la anatomía foliar de Poaceae ha sido ampliamente reconocida en la literatura agrostológica, especialmente a nivel de subfamilia (Prat 1932, 1936, 1948, 1961, Tateoka et al. 1959, Metcalfe 1960, Baum 1971, Ellis 1979, Matthei 1982, Arriaga 1983, Peterson et al. 1989, Zuloaga et al. 1993, Herrera \& Grant 1994, Baeza 1997). Tanto la epidermis abaxial de la lámina foliar (Tateoka et al. 1959, Stewart 1965, Barkworth 1981, Aiken \& Lefkovitch 1984, Dávila \& Clark 1990, Baeza 1997), como la epidermis de la lígula (Chaffey 1983, 1984, 1985, 1994) y de las brácteas de la espiguilla (glumas, lemmas y páleas) (Clark \& Gould 1975, Terrel \& Wergin 1981, Terrel et al. 1983, Thomasson 1978, 1986, Acedo \& Llamas 2001, Finot et al. 2006), han sido reconocidas como una fuente importante de caracteres con valor taxonómico, y utilizadas en muchos casos para distinguir géneros y delimitar especies.

En general, existen relativamente pocos trabajos que den a conocer la anatomía foliar del género Trisetum Pers., en especial, de las especies americanas. Hernández-Torres \& Koch (1988) y HernándezTorres \& Engleman (1995) estudiaron la sección transversal y la epidermis abaxial en unas 12 especies de Trisetum. Concluyen que los datos anatómicos son importantes para fundamentar la sinonimia de algunas especies (T. rosei Scribn. \& Merr. con T. spicatum (L.) K.Richt., T. evolutum (E.Fourn.) Hitchc. con $T$. deyeuxioides (Kunth) Kunth y T. palmeri Hitchc. con T. viride E.Fourn.) y para fusionar los géneros Trisetum y Peyritschia E.Fourn.

La mayor parte de los estudios anatómicos en Trisetum han sido realizados en especies europeas. Paunero (1950) incluye observaciones anatómicas de varias especies en su tratamiento del género Trisetum (bajo Trisetaria Forsk.). Posteriormente, Metcalfe (1960) describe la anatomía de T. flavescens (L.) P.Beauv. Chrtek \& Jirásek (1963) y Chrtek (1965) estudian la anatomía foliar y la epidermis abaxial en varias especies europeas. Sobre la base de los caracteres anatómicos observados (distribución del esclerénquima, desarrollo de las células buliformes y epidermis abaxial), en conjunto con la morfología externa, Chrtek (1965) divide el género en cuatro subgéneros (Trisetum, Distichotrisetum Chrtek, Glaciotrisetum Chrtek y Graciliotrisetum Chrtek) y reconoce tres nuevas secciones en el Subg. Trisetum, que queda así constituido por cinco secciones (Sect.
Trisetum, Trisaetera Asch. \& Graeb., Rigida Chrtek, Hispanica Chrtek y Carpatica Chrtek). Gamisans (1971) describe una nueva especie europea, $T$. conradiae, que asigna al subg. Graciliotrisetum sobre la base de los caracteres anatómicos. Observaciones detalladas de la anatomía foliar de Trisetum se encuentran en Conert (1987), también para especies de la flora de Europa (Trisetum alpestre (Host) P.Beauv., T. argenteum (Willd.) Roem. et Schultes, $T$. distichophyllum (Vill.) P.Beauv., T. flavescens, $T$. loeflingianum (L.) Presl y T. spicatum subsp. ovatipaniculatum Hultén ex Jonsell).

En el presente trabajo se estudió la epidermis abaxial de la lámina foliar de 37 especies de Trisetum, con el objeto de evaluar su significado taxonómico.

\section{MATERIALES Y METODOS}

Las muestras de hojas se tomaron de material de los herbarios B, BA, BAA, CONC, CR, M, QCA, SGO y US. En lo posible, las muestras se tomaron en la zona media de la penúltima hoja de una innovación. Para la preparación de la epidermis abaxial se siguió la técnica de Metcalfe (1960). Las muestras fueron hidratadas en solución de detergente por 10-30 minutos y se procedió, bajo microscopio estereoscópico, a eliminar la epidermis adaxial y tejidos subyacentes con ayuda de un bisturí, hasta aislar la epidermis abaxial. Las epidermis aisladas fueron aclaradas en solución de hipoclorito de sodio, lavadas en agua corriente y montadas en gelatina-glicerina para su observación con microscopio óptico. Las fotografías se tomaron con una cámara fotográfica digital Canon Power Shot G6 adosada a un microscopio Zeiss equipado con objeti$\operatorname{vos} 10 x, 40 x$ y 100x.

Observaciones de la epidermis adaxial con microscopio electrónico de barrido (MEB) fueron realizadas para algunas especies. Las hojas fueron hidratadas, secadas a punto crítico ( $\mathrm{O}$ líquido, $\left.31,1^{\circ} \mathrm{C}, 80 \mathrm{~atm}\right)$, metalizadas con oro a $500 \AA$ de espesor en un metalizador Edwars $\$ 150$ y observadas en un microscopio Etec Autoscan U-1 en el Laboratorio de Microscopía Electrónica de la Universidad de Concepción.

La terminología utilizada corresponde a la propuesta por Ellis (1976, 1979). Los caracteres y estados observados se señalan en la Tabla II. Las dimensiones se dan en micrones $(\mu \mathrm{m})$. Se estudiaron 35 taxa pertenecientes a 29 especies del género Trisetum s.s. 
Adicionalmente se incluyó especies previamente tratadas en Trisetum, que han sido transferidas a otro género: Deschampsia brasiliensis (LouisMarie) Valencia (= Trisetum brasiliense LouisMarie), Helictotrichon bulbosum (Hitchc.) Parodi (= T. bulbosum Hitchc.) y Peyritschia deyeuxioides (Kunth) Finot $(=T$. deyeuxioides Kunth). Los nombres completos de los taxa estu- diados, incluyendo sus autores y los especimenes de herbario utilizados se señalan en la Tabla I. Se confeccionó una matriz básica de datos (35 OTU x 17 caracteres), a la que se aplicó análisis de cluster (UPGMA) basado en el índice de distancia de Dice y análisis de componentes principales (ACP) utilizando el programa InfoStat versión 2004 (InfoStat 2004).

TABLA I. Lista de las especies estudiadas, especímenes estudiados, herbarios y acrónimos. Los especímenes ilustrados se señalan con un asterisco $(*)$.

TABLE I. List of studied species, studied specimens, herbaria and acronyms. Illustrated specimens are marked with an asterisk $(*)$.

MATERial ESTUDiado

ACRÓNIMO

Deschampsia brasiliensis Louis-Marie. BRASIL, Itataia, Río de Janeiro, 2200-2400 m, 17-I-1925, Chase 8304* (US).

BRAS

Helictotrichon bulbosum (Hitchc.) Parodi. CHILE, VIII Región, camino entre Chillán y Bulnes km 419,5, en espinal de Acacia caven, 28-XII-2004, Finot \& Baeza 2066* (CONC).

BULB

Peyritschia deyeuxioides (Kunth) Finot. ECUADOR, Bolívar, 14,5 km E of Guaranda on road to Río Bamba, 2950 m, 24-V-1990, Peterson \& Judziewicz 9300 (QCA).

DEYE

Trisetum ambiguum Rúgolo \& Nicora. ARGENTINA, Santa Cruz, Güer Aike, Estancia La Carlota, sección San Elías, 57²4', 71³2', 19-I-1978, Roig, Anchorena, Méndez \& Ambrosetti 103* (SI); Tierra del Fuego, norte de Río Grande, Estancia María Behety, 27-I-1955, Soriano 4847 (BAA).

AMBI

T. angustum Swallen. GUATEMALA, San Marcos, 13-II-1940, Steyermark 35525*(US, tipo).

ANGU

T. barbinode Trin. var. barbinode. CHILE, VIII Región, Prov. Ñuble, Refugio Club Andino de Chillán, Shangri-La, 1500 m, 3652'S, 71³0'W, 30-31-I-1965, Garaventa 4681 (CONC 88159); entre Valle Hermoso y Termas de Chillán, 12-I-2005, Finot \& Baeza 2070 (CONC); Prov. Bío-Bío, P.N. Laguna del Laja, Las Lagartijas, 13-I-2005, Finot \& Baeza 2073* (CONC).

BARB

T. barbinode var. hirtiflorum (Hack.) Louis-Marie. CHILE, VIII Región, Prov. Nuble, Termas de Chillán, Faldeos del Volcán Chillán, 2200-2300 m, 3654’S, 71²4’W, 9-III-1968, Ricardi 5604 (CONC 88158).

HIRT

T. barbinode var. sclerophyllum (Hack.) Finot. ARGENTINA, Neuquén, Río Negro, año 1949, Pérez Moreau s.n. (BA).

SCLE

T. caudulatum Trin. CHILE, VIII Región, Concepción, San Pedro, en las lomas, 3650'S, 7306 'W, 10 m, 10-XII-1946. Pfister s.n.* (CONC).

CAUD

T. cernuum Trin. subsp. canescens (Buckl.) Calder \& R.L.Taylor. CANADA, Columbia Británica, Mts. near Ainsworth, Kootamie Lake, 2800 ft., 7-VII-1890, Macoun 107 (US). U.S.A., Pine Creek, Sierra Nevada, Inyo County, near Round Valley, 8000 ft, 10-VII-1932, Durán 3333 (CONC).

CANE

T. cernuum Trin. subsp. cernuum. CHILE, X Región, Prov. Valdivia, Chihuio, Hito de Portezuelo Ipela, 1400 m, 4009'S, 7149'W, 21-I-1997, Godoy 119 (CONC 141657); XI Región, Prov. Aysén, Parque Nacional Trapananda, 900 m, 45²5'S, 7158' W, III-1987, Schlegel 8070 (CONC 115649).

CERN 
Epidermis foliar de Trisetum (Poaceae): Finot, V.

Continuación Tabla I.

T. curvisetum Morden \& Valdés-Reyna. MEXICO, Nuevo León, Sitio La Encantada-La Tinaja on road to La Tinaja, $23^{\circ} 53^{\prime} \mathrm{N}$, 9947'W, 2500 m, 21-IX-2002, Peterson, Valdés-Reyna \& Sosa Morales 16764* (US).

CURV

T. durangense P.M.Peterson, Finot \& Soreng. MEXICO, Durango, $56 \mathrm{~km} \mathrm{~W}$ of Durango on HWY 40 towards Mazatlán, 23 54' N, 105º 01' W, 2500 m, 6-X-2002, Peterson \& Brothers 16964 (CONC, US).

DURA

T. filifolium Scribn. MEXICO, Chihuahua, Sánchez, 8000 ft, 12-X-1910, Hitchcock 7682*(US).

FILI

T. flavescens (L.) P.Beauv. U.S.A., Washington: Walla Walla, 31-V-1900, Leckenby 19** (US).

FLAV

T. howellii Hitchc. ECUADOR, Galápagos, Isla Santa Cruz (Indefatigable), Puntudo, 17-III-1977, A. \& H. Adsersen 1413 (QCA).

HOWE

T. irazuense Hitchc. ECUADOR, Pichincha, Reserva Geobotánica Pasochoa, 0²1'S, 78²9'W, 3100-3400 m, 23-II-1992, Laegaard 101414 (QCA).

IRAZ

T. ligulatum Finot \& Zuloaga. MEXICO, Jalisco, Nevado de Colima, 20 mi SW of Ciudad Guzmán and $14 \mathrm{mi}$ SW of paved Highway up road towards the Nevado, 3810 m, 23-XI-1995, Peterson \& Blackburn 13778*(US).

LIGU

T. longiglume Hack. CHILE, Región Metropolitana, Cajón Las Leñas, Arroyo et al. 94454* (CONC).

LONG

T. mattheii Finot. CHILE, I Región, Tarapacá, camino Arica a Chapiquiña Km 111, 4100 m, 9-II1964, Marticorena, Matthei \& Quezada 86* (CONC 88160, tipo).

MATT

T. nancaguense Finot. CHILE, VIII Región, Prov. Concepción, camino entre Concepción y Bulnes Km 42, 250 m, 36²99'S, 7244'W, 16-XII-1967, Villarroel \& Weldt 151* (CONC).

NANC

T. oreophilum Louis-Marie var. oreophilum. ECUADOR, Azuai, P.N. Cajas, NW Cuenca along Río Miguir, 3480 m, 21-IV-1990, Peterson et al. 8866* (US).

OREO

T. orthochaetum Hitchc. U.S.A., Montana, Bitterroot Mountains, Missoula Co., 1200 m, near Lolo Hot Spring, 23-VII-1908, Chase 5129 (US, tipo).

ORTH

T. palmeri Hitchc. MEXICO. Coahuila, $55.3 \mathrm{~km}$ SE of Saltillo and $16.6 \mathrm{~km}$ SE of Jame on road to Sierra La Viga, 3400 m, 26-IX-1990, Peterson, Annable \& Valdés-Reyna 10065 (US). Nuevo León, Sierra Madre Oriental, $11.4 \mathrm{mi}$ W of Dieciocho de Marzo up road towards Cerro Potosi, 3130 m, 18-X-1995, Peterson \& Knowles 13336 (US).

PALM

T. phleoides (d'Urv.) Kunth. ARGENTINA, Tierra del Fuego Isla de los Estados, Puerto Abrigado, 16-I-1934, Castellanos s.n. (BA), Río Fuego, 9-I-1919, Pico s.n.* (BAA). CHILE, XII Región,

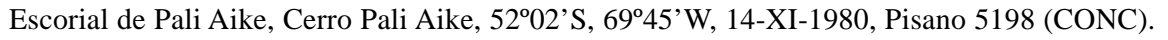

PHLE

T. preslei (Kunth) E.Desv. ARGENTINA, Prov. Mendoza, on road above Las Cuevas, below Cristo Redentor, 3510 m, 26-II-1967, H. \& B. Mooney 546 (CONC). CHILE, Región Metropolitana, Cajón del Maipo, 2850 m, II-1948, Gunckel 20297* (US 2044773).

PRES

T. pringlei (Scribn. ex Beal) Hitchc. COSTA RICA, San José, Cordillera de Talamanca, Cerro de La Muerte, 3250 m, 13-VII-1968, Pohl \& Davidse 10694*(CR).

PRIN 
Gayana Bot. 63(2), 2006

Continuación Tabla I.

T. projectum Louis-Marie. USA, California, dry woods along Line Creek, Huntington Lake, 23-VII1923, Swallen 853* (US).

PROJ

T. rosei Scribn. \& Merr. MEXICO, Puebla, North side of Popocatepetl; above timberline in black sandy soil, 11-IX-1957, Beaman 1729* (US).

ROSE

T. sibiricum Rupr. U.S.A., Alaska, Ogotoruk Creek, 30-31-VII-1960, Hultén s.n.* (S).

T. spellenbergii Soreng, Finot \& P.M.Peterson. MEXICO, Sonora, Sierra Madre Occidental, 9.6 mi E of Maycoba on Highway 16 towards Yepachic, 1420 m, $28^{\circ} 26^{\prime} \mathrm{N}, 108^{\circ}$ 33' W, 14-X-1992, Peterson \& Annable 12509* (US).

T. spicatum (L.) K.Richt. var. spicatum. CHILE, VIII Región, Prov. Bío-Bío, P.N. Laguna del Laja, Antuco, 13-I-2005, Finot \& Baeza 2072* (CONC). CHILE, XI Región, Prov. Aysén, Aysén,

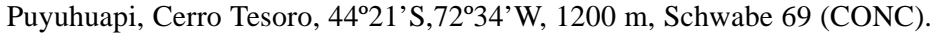

T. tonduzii Hitchc. COSTA RICA, Cartago, cinder cone summit of Volcán Irazú, 3200 m, 3-VII1968, Pohl \& Davidse 10618* (US).

TOND

T. viride (Kunth) Kunth. MEXICO, Durango, Sierra Madre Occidental, $2.4 \mathrm{mi} \mathrm{N}$ of Borbollones, $\mathrm{N}$ of highway 40, $2590 \mathrm{~m}, 25-\mathrm{X}-1995$, Peterson et al. 13432 (US).

VIRI

T. virletii E.Fourn. MEXICO, Amecameca, Vicinity of La Cima railroad station, on top of the Serjana de Ajusco, 3030-3060 m, 1907’ N, 99¹2’W, 23-I-1963, Iltis \& Iltis 1671-a* (US).

VIRL

TABLA II. Caracteres y estados de carácter utilizados en los análisis fenéticos.

TABLE II. Characters and character states used in the phenetic analyses.

1. Zonación costal/intercostal (zci): 0 = inconspicua, $1=$ conspicua.

2. Forma de las células largas intercostales (cli): $0=$ hexagonales, $1=$ rectangulares a hexagonales, $2=$ hexagonales.

3. Longitud de las células largas intercostales (lcli): cuantitativo $(\mu \mathrm{m})$

4. Pared anticlinal de las células largas intercostales (pacli): $0=$ no ondulada, $1=$ ondulada.

5. Grosor de la pared anticlinal de las células largas intercostales (gpacli): $0=$ no engrosada, $1=$ engrosada.

6. Células buliformes (cbul): $0=$ ausentes, $1=$ presentes.

7. Aguijones (ag): $0=$ ausentes, $1=$ presentes.

8. Macropelos (mp): $0=$ ausentes; $1=$ presentes.

9. $\mathrm{N}^{\mathrm{o}}$ filas de células largas intercostales (nfcli): $0=$ menos de $10 ; 1=10$ o más.

10. Células cortas intercostales (cci): $0=$ ausentes, $1=$ presentes.

11. Pared anticlinal de las células largas costales (paclc): $0=$ levemente ondulada, $1=$ profundamente ondulada.

12. Grosor pared anticlinal células largas costales (gpaclc): $0=$ no engrosada, $1=$ moderadamente engrosada, 2 = gruesa.

13. Aguijones costales $(\mathrm{agc}): 0=$ ausentes, $1=$ presentes

14. Cuerpos silíceos costales (csc): $0=$ elongados, $1=$ equidimensionales.

15. Estomas (est): $0=$ ausentes, $1=$ presentes

16. Longitud de los estomas (lest): cuantitativo $(\mu \mathrm{m})$.

17. Longitud células largas costales (lclc): cuantitativo $(\mu \mathrm{m})$ 
Epidermis foliar de Trisetum (Poaceae): FINOT, V.

\section{RESULTADOS}

La epidermis abaxial de Trisetum s.s. muestra, en la mayor parte de las especies, una clara zonación costal/intercostal mientras en $T$. durangense, $T$. filifolium, T. palmeri y T. rosei (Fig. 28) la zonación costal/intercostal es inconspicua; las zonas intercostales constan de 3-30 filas de células de ancho y están conformadas sólo por células largas o bien por células largas y células cortas; las células largas poseen contorno hexagonal (Figs. 1H, 2B, 2C, 2H, 4C, 4E) o rectangular (Figs. 1D, 1E, 2A, $2 \mathrm{E}, 2 \mathrm{~F}, 3 \mathrm{~B}, 3 \mathrm{E}, 3 \mathrm{G}, 3 \mathrm{H}, 4 \mathrm{~B}, 4 \mathrm{D}, 5 \mathrm{~A}, 5 \mathrm{C}, 5 \mathrm{D}), \mathrm{y}$ alcanzan 35-570 $\mu \mathrm{m}$ de largo, siendo muy largas en algunas especies como T. cernuum (300-500 $\mu \mathrm{m})$, T. irazuense (290-570 $\mu \mathrm{m})$ o relativamente cortas, como en $T$. durangense (40-110 $\mu \mathrm{m}), T$. mattheii (35-90 $\mu \mathrm{m}$, Fig. 14), T. oreophilum (55-75 $\mu \mathrm{m}), T$. rosei (45-60 $\mu \mathrm{m}$, Fig. 4D); las paredes anticlinales de las células largas son profundamente onduladas (Figs. 1D, 2A, 4B, 5C, 5D) o levemente onduladas (Figs. 1H, 2B, 2F, 3H, 4D, 5A) a no onduladas (Figs. 2D, 2E, 2H, 3B, 3E, 4C, 4E, 4F), engrosadas (Fig. 5A) o no engrosadas (Fig. 4F); las células cortas intercostales están ausentes en la mayor parte de las especies; están presentes en T. angustum (Fig. 1D), T. curvisetum (Fig. 1H), T. durangense, T. filifolium, T. palmeri, T. pringlei (Fig. 4B), T. rosei (Fig. 4D), T. tonduzii (Fig. 5A), T. viride (Fig. 5C) y $T$. virletii (Fig. 5D) y se disponen en pares sílicosuberosos, con la célula silícea usualmente redondeada y la suberosa cuadrada a rectangular, más ancha que larga; aguijones ausentes o presentes en las zonas intercostales (Fig. 3G-H); macropelos generalmente ausentes, más raramente presentes (Figs. $2 \mathrm{H}, 3 \mathrm{~F}, 4 \mathrm{~B}, 4 \mathrm{C}$ ); estomas ausentes o presentes, de 25-35 $\mu \mathrm{m}$ de largo. Las zonas costales se componen de 1-15 filas de células largas de contorno generalmente rectangular (Figs. 1G-H, 3A, 4B, 4H, 5C), de $35-270 \mu \mathrm{m}$ de largo, con paredes anticlinales generalmente onduladas; aguijones generalmente presentes; cuerpos silíceos elongados (Figs. 1E-G, $3 \mathrm{~A}, 3 \mathrm{D}, 4 \mathrm{H})$ o redondeados a rectangulares, más anchos que largos (Figs. 1D, 4B, 5C), solitarios, en hileras de pocas células o en pares sílico-suberosos.

En la epidermis adaxial (Fig. 6) se observó diferenciación costal/intercostal (Fig. 6A), con estomas restringidos a las zonas intercostales, provistos de células subsidiarias con lados paralelos (Fig. 6A-B). Las células epidérmicas adaxiales pue- den ser, al igual que las abaxiales, rectangulares (Fig. 6E) o fusiformes (Fig. 6F).

ANÁLISIS DE AGRUPAMIENTOS

El fenograma UPGMA resultante utilizando el índice de distancia de Dice, permite distinguir cuatro grupos de especies (Fig. 7):

A. El primer grupo (A) comprende sólo a Deschampsia brasiliensis, que se une a las restantes especies en el fenograma (Fig. 7) con muy baja similitud $(\mathrm{D}=0,90)$. Se caracteriza por poseer epidermis abaxial con diferenciación costal/ intercostal conspicua; zonas costales formadas por 3-8 filas de células de ancho, a veces más anchas que las zonas intercostales; zonas intercostales formadas por 2-4 filas de células de ancho; células largas intercostales de contorno rectangular (100-200 $\mu \mathrm{m}$ de largo), con paredes anticlinales irregularmente onduladas; zonas intercostales sin estomas, aguijones, macropelos ni células cortas; células cortas restringidas a las zonas costales, dispuestas en pares sílicosuberosos, con la célula suberosa rectangular, más ancha que larga y la silícea redondeada (Fig. 1AB).

B. El segundo grupo (B) también está formado por una sola especie, Helictotrichon bulbosum que se une a las restantes especies a una distancia $\mathrm{D}=0,88$, lo que indica también una muy baja similitud en los caracteres epidérmicos. Posee epidermis abaxial con zonación costal/intercostal conspicua; zonas intercostales de 3-12 filas de células de ancho; zonas costales generalmente más angostas que las zonas intercostales formadas por 8-10 filas de células; células largas intercostales de contorno hexagonal (280-300 $\mu \mathrm{m}$ de largo), con paredes anticlinales rectas; estomas, aguijones, macropelos y células cortas intercostales ausentes; células cortas restringidas a las zonas costales; células silíceas solitarias o en hileras, elongadas, con los márgenes laterales ondulados (Fig. 1C).

C. El tercer grupo (C) comprende ocho especies: Trisetum pringlei, T. virletii, T. viride, $T$. palmeri, T. tonduzii, T. rosei, $T$. filifolium y $T$. durangense que se unen a las restantes especies a una distancia $\mathrm{D}=0,745$, que indica una baja similitud con el grupo D. Las especies con mayor similitud son $T$. tonduzii-T. rosei $(\mathrm{D}=0,23)$ y $T$. filifolium-T. durangense $(\mathrm{D}=0,25)$. Las es- 
pecies de este grupo poseen zonación costal/ intercostal excepto $T$. durangense, T. filifolium, T. palmeri y T. rosei (Fig. 4D), donde las zonas costales e intercostales no se distinguen claramente, presentan células cortas intercostales asociadas en pares sílico-suberosos, con la célula suberosa generalmente cuadrada a rectangular más ancha que larga y la silícea de contorno redondeado, poseen células largas intercostales siempre rectangulares (Figs. 5A, 5C), con paredes anticlinales profundamente onduladas (Fig. 5C) a levemente onduladas (Figs. 4D, 5A), estomas ausentes (excepto T. virletii), aguijones generalmente presentes, especialmente en los zonas costales y macropelos ausentes (excepto $T$. pringlei). Con la excepción de $T$. rosei, las especies de este grupo pertenecen al subg. Deschampsioideum.

D. El cuarto grupo (D) comprende la mayor parte de los taxa estudiados (22 especies y 3 variedades): Peyritschia deyeuxioides (Kunth) Finot, Trisetum ambiguum Rúgolo \& Nicora, $T$. angustum, T. barbinode Trin. var. barbinode, $T$. barbinode var. hirtiflorum (Hack.) Louis-Marie, T. barbinode var. sclerophyllum (Hack. ex Stuck.) Finot, T. caudulatum Trin., T. cernuum Trin. subsp. cernuum, T. cernuum subsp. canescens (Buckl.) Calder \& R.L.Taylor, T. curvisetum, T. flavescens, T. howellii Hitchc., T. irazuense, T. ligulatum Finot \& Zuloaga, T. longiglume Hack., T. mattheii, T. nancaguense Finot, T. oreophilum, T. orthochaetum Hitchc., T. phleoides (d'Urv.) Kunth, T. preslei (Kunth) E.Desv., T. projectum Louis-Marie, T. spellenbergii Soreng, Finot \& P.M.Peterson, T. sibiricum Rupr. y T. spicatum. Este grupo se caracteriza por carecer de células cortas intercostales (presentes solamente en las especies del grupo C), zonas costales de 1-15 células de ancho, más angostas que las intercostales (Figs. 2C, 2H), zonas intercostales de 3-25 células de ancho, células largas intercostales rectangulares a hexagonales, con paredes anticlinales no onduladas a levemente onduladas, estomas generalmente presentes (ausentes en T. howellii, T. irazuense, T. spellenbergii), aguijones generalmente presentes (Figs. 3C, 3H), macropelos ausentes o presentes, cuerpos silíceos en hileras, pares o solitarios (Figs. 3A, 4F), a veces en pares sílico-suberosos, generalmente elongados, con los márgenes ondulados. Con la excepción de $P$. deyeuxioides, las especies de este grupo pertenecen al subg. Trisetum.

ANÁLISIS DE COMPONENTES PRINCIPALES

La distribución de las OTUs (taxa) y de las variables (caracteres) en el espacio conformado por los dos primeros componentes principales se muestra en la Fig. 8. El primer componente explica un $32 \%$ de la variabilidad de la matriz original en tanto que los componentes 2 y 3 explican un $14 \%$ y $11 \%$, respectivamente. La varianza explicada por los tres primeros componentes fue de $57 \%$. Los caracteres que otorgan la mayor contribución al primer componente son la longitud de las células largas intercostales (LCLI), presencia/ausencia de células cortas intercostales (CCI), número de filas de células largas intercostales (NFCLI), presencia/ausencia de aguijones costales (AGC), pared anticlinal de las células largas costales (PACLC) y pared anticlinal de las células largas intercostales (PACLI). Al segundo componente contribuyen, principalmente, el grosor de la pared anticlinal de las células largas costales (GPACLC) y la longitud de las células largas costales (LCLC).

En general, la distribución de las especies en el espacio generado por los dos primeros componentes coincide con los grupos reconocidos en el análisis de agrupamientos. Las especies del subg. Deschampsioideum (Grupo C) se separan de las especies del subg. Trisetum (Grupo D) a lo largo del primer componente. Se observa, sin embargo, que T. pringlei (Grupo C') se separa de las especies del grupo C (T. virletii, $T$. viride, $T$. palmeri, T. tonduzii, T. rosei, $T$. filifolium y $T$. durangense) a lo largo del segundo componente. Trisetum angustum, que forma parte del grupo D en el análisis de agrupamientos, se separa también a lo largo del segundo componente, acercándose a T. pringlei. Deschampsia brasiliensis y Helictotrichon bulbosum se apartan hacia el extremo inferior del segundo componente.

\section{DISCUSION}

Los resultados sugieren que los caracteres de la epidermis abaxial de la lámina foliar son útiles para comprender las relaciones sistemáticas en el género Trisetum, especialmente para distinguir 
Epidermis foliar de Trisetum (Poaceae): FinOT, V.

los subgéneros Trisetum y Deschampsioideum. A nivel genérico, aunque sólo se incluyó una especie de Peyritschia en este estudio ( $P$. deyeuxioides), los resultados coinciden con los de Hernández-Torres \& Koch (1988) y Hernández-Torres \& Engleman (1995), en que la anatomía foliar no permite distinguir Peyritschia de Trisetum s.s. En cambio, los caracteres epidérmicos sí sustentan la separación de Deschampsia brasiliensis (= Trisetum brasiliense) y Helictotrichon bulbosum (= Trisetum bulbosum), especies que se unen al fenograma con muy bajo índice de similitud.

Las especies de Trisetum s.s. se reúnen en dos grupos que, en general, coinciden con la clasificación infragenérica propuesta por Finot et al. (2004, 2005, 2006). Trisetum virletii, T. viride, T. palmeri, T. tonduzii, T. filifolium y $T$. durangense, que forman parte del grupo $\mathrm{C}$, pertenecen al subgénero Deschampsioideum, que se caracteriza por poseer panículas laxas, abiertas, espiguillas con glumas subiguales, a menudo igualando al conjunto de los antecios, lemma redondeada en el dorso, con el ápice bidentado o terminado en 2(-4) setas apicales, aristada desde la porción media del dorso (Finot et al., 2004). La epidermis abaxial de estas especies muestra presencia de células cortas intercostales, con células silíceas redondeadas y células suberosas cuadradas o más anchas que largas, dispuestas siempre en pares sílico-suberosos, y células largas generalmente rectangulares, a veces profundamente onduladas, a veces sin zonación costal/ intercostal notable. Estos caracteres permiten distinguirlos del Subg. Trisetum, que carece de células cortas intercostales, estando éstas siempre restringidas a las zonas costales, con células silíceas elongadas y dispuestas solitarias o en cortas hileras de células, a veces en pares sílicosuberosos y zonación costal/intercostal siempre notable. Morfológicamente, el subgénero Trisetum se caracteriza por poseer panículas espiciformes (Sect. Trisaetera) o abiertas (Sect. Trisetum), espiguillas con glumas desiguales, la inferior menor que la superior, menores, iguales o mayores que el conjunto de los antecios, lemas lanceoladas, aquilladas, con el ápice terminado en 2 ó 4 setas que derivan de la prolongación apical de los nervios intermedios y marginales de la lemma, y la arista inserta en el tercio superior del dorso. Aunque los caracteres morfológicos permiten reconocer las secciones Trisetum y Trisaetera, los caracteres epidérmicos estudiados no permiten separarlas en los análisis realizados. Existe, no obstante, una tendencia entre las especies de la Sect. Trisetum ( $T$. cernuum var. cernuum, $T$. cernuum var. canescens, T. curvisetum, T. irazuense, $T$. flavescens, T. orthochaetum) a poseer epidermis abaxial con células largas de mayor longitud y de contorno hexagonal en comparación con las especies de la Sect. Trisaetera, con células largas usualmente menores y rectangulares.

Es interesante notar que aunque el valor sistemático de la epidermis abaxial de la hoja a nivel específico es limitado, resulta útil para separar a $T$. rosei de $T$. spicatum, considerados sinónimos por Hernández-Torres \& Koch (1988). Ambas especies pertenecen a la Sect. Trisaetera (Finot et al. 2004). No obstante, $T$. rosei comparte las características epidérmicas que presentan las especies del Subg. Deschampsioideum, principalmente la presencia de células cortas intercostales de carácter ausente en T. spicatum, así como en las restantes especies del Subg. Trisetum. Además, este carácter se encuentra también en $T$. pringlei, cuya posición sistemática permanece dudosa (Finot et al. 2004). El subgénero Deschampsioideum se distribuye exclusivamente en México y Centroamérica; Trisetum pringlei, por su parte, crece en México, Guatemala, Costa Rica y Panamá y T. rosei es endémico de México (Finot et al. 2004). En consecuencia, la presencia de células cortas intercostales estaría restringida a especies de México y Centro-américa y no constituye una sinapomorfía para el Subg. Deschampsioideum. 
TABLA III. Matriz de datos de los 35 OTU x 17 caracteres utilizada en los análisis de agrupamientos y de componentes principales. Los acrónimos corresponden a las especies como se indica en la Tabla I.

TABLE III. Data matrix of 35 OTU x 17 characters used in cluster analysis and principal component analysis. Acronyms correspond to species as indicated in Table I.

\begin{tabular}{|c|c|c|c|c|c|c|c|c|c|c|c|c|c|c|c|c|c|}
\hline OTUs & 1 & 2 & 3 & 4 & 5 & 6 & 7 & 8 & 9 & 10 & 11 & 12 & 13 & 14 & 15 & 16 & 17 \\
\hline 1.AMBI & 1 & 0 & 180 & 1 & 0 & 0 & 1 & 0 & 2 & 0 & 1 & 1 & 1 & 0 & 1 & 35 & 70 \\
\hline 2.ANGU & 1 & 0 & 115 & 1 & 0 & 0 & 0 & 0 & 1 & 1 & 0 & 1 & 0 & 1 & 1 & 30 & 85 \\
\hline 3.BARB & 1 & 0 & 150 & 0 & 0 & 0 & 1 & 0 & 0 & 0 & 0 & 1 & 1 & 0 & 1 & 35 & 120 \\
\hline 4.BRAS & 1 & 0 & 150 & 0 & 0 & 0 & 0 & 0 & 0 & 0 & 0 & 1 & 0 & 1 & 0 & 0 & 95 \\
\hline 5.BULB & 1 & 1 & 290 & 0 & 0 & 0 & 0 & 0 & 0 & 0 & 0 & 0 & 0 & 0 & 0 & 0 & 45 \\
\hline 6.CANE & 1 & 1 & 300 & 0 & 0 & 0 & 1 & 0 & 1 & 0 & 1 & 0 & 1 & 0 & 1 & 35 & 195 \\
\hline 7.CAUD & 1 & 1 & 190 & 0 & 0 & 0 & 0 & 1 & 0 & 0 & 1 & 0 & 0 & 0 & 1 & 30 & 55 \\
\hline 8.CERN & 1 & 1 & 400 & 0 & 0 & 0 & 1 & 0 & 1 & 0 & 1 & 0 & 1 & 0 & 1 & 35 & 195 \\
\hline 9.CURV & 1 & 2 & 215 & 0 & 0 & 0 & 2 & 0 & 1 & 1 & 1 & 0 & 1 & 0 & 1 & 25 & 70 \\
\hline 10.DEYE & 1 & 0 & 400 & 0 & 0 & 0 & 0 & 0 & 1 & 0 & 0 & 0 & 1 & 0 & 1 & 25 & 195 \\
\hline 11.DURA & 0 & 0 & 75 & 1 & 0 & 0 & 2 & 0 & 1 & 1 & 1 & 2 & 1 & 1 & 0 & 0 & 75 \\
\hline 12.FILI & 0 & 0 & 70 & 1 & 0 & 0 & 2 & 0 & 0 & 1 & 1 & 2 & 1 & 1 & 0 & 0 & 70 \\
\hline 13.FLAV & 1 & 1 & 315 & 0 & 0 & 0 & 1 & 0 & 1 & 1 & 0 & 0 & 0 & 1 & 1 & 25 & 75 \\
\hline 14.HIRT & 1 & 0 & 170 & 0 & 0 & 0 & 1 & 0 & 0 & 0 & 0 & 1 & 1 & 0 & 1 & 35 & 85 \\
\hline 15.HOWE & 1 & 2 & 210 & 0 & 0 & 0 & 0 & 0 & 0 & 0 & 0 & 0 & 1 & 0 & 0 & 0 & 195 \\
\hline 16.IRAZ & 1 & 2 & 430 & 0 & 0 & 0 & 1 & 1 & 1 & 0 & 0 & 1 & 1 & 0 & 0 & 0 & 185 \\
\hline 17.LIGU & 1 & 0 & 185 & 0 & 0 & 0 & 1 & 1 & 0 & 0 & 0 & 1 & 0 & 0 & 1 & 30 & 110 \\
\hline 18.LONG & 1 & 1 & 140 & 0 & 0 & 0 & 1 & 0 & 1 & 0 & 0 & 1 & 1 & 0 & 1 & 50 & 95 \\
\hline 19.MATT & 1 & 1 & 60 & 0 & 0 & 0 & 0 & 1 & 1 & 0 & 0 & 0 & 1 & 0 & 1 & 25 & 50 \\
\hline 20.NANC & 1 & 1 & 185 & 0 & 0 & 0 & 1 & 1 & 2 & 0 & 1 & 1 & 1 & 0 & 1 & 35 & 70 \\
\hline 21.OREO & 1 & 1 & 65 & 0 & 0 & 0 & 1 & 1 & 0 & 0 & 1 & 1 & 1 & 0 & 1 & 25 & 65 \\
\hline 22.ORTH & 1 & 2 & 225 & 0 & 0 & 1 & 0 & 0 & 1 & 0 & 0 & 1 & 0 & 0 & 1 & 50 & 195 \\
\hline 23.PALM & 0 & 0 & 85 & 1 & 1 & 0 & 2 & 0 & 0 & 1 & 1 & 2 & 1 & 1 & 0 & 0 & 85 \\
\hline 24.PHLE & 1 & 1 & 130 & 0 & 0 & 0 & 1 & 1 & 0 & 0 & 1 & 1 & 1 & 0 & 1 & 35 & 95 \\
\hline 25.PRES & 1 & 0 & 120 & 0 & 0 & 0 & 1 & 0 & 0 & 0 & 0 & 1 & 1 & 0 & 1 & 25 & 60 \\
\hline 26.PRIN & 1 & 0 & 85 & 1 & 0 & 0 & 1 & 1 & 0 & 1 & 1 & 1 & 0 & 2 & 0 & 0 & 45 \\
\hline 27.PROJ & 1 & 1 & 270 & 0 & 0 & 1 & 2 & 1 & 2 & 0 & 0 & 0 & 1 & 0 & 1 & 35 & 80 \\
\hline 28.ROSE & 0 & 0 & 50 & 1 & 1 & 0 & 2 & 0 & 2 & 1 & 1 & 2 & 1 & 1 & 0 & 0 & 50 \\
\hline 29.SCLE & 1 & 0 & 210 & 0 & 0 & 0 & 1 & 0 & 0 & 0 & 0 & 1 & 1 & 0 & 1 & 50 & 95 \\
\hline 30.SIBI & 1 & 1 & 250 & 0 & 0 & 0 & 0 & 0 & 2 & 0 & 0 & 0 & 0 & 0 & 1 & 50 & 150 \\
\hline 31.SPEL & 1 & 1 & 250 & 0 & 0 & 0 & 1 & 1 & 0 & 0 & 1 & 0 & 1 & 2 & 0 & 0 & 80 \\
\hline 32.SPIC & 1 & 1 & 150 & 0 & 0 & 0 & 1 & 0 & 1 & 0 & 1 & 1 & 1 & 0 & 1 & 35 & 65 \\
\hline 33.TOND & 1 & 0 & 130 & 1 & 1 & 0 & 0 & 0 & 1 & 1 & 1 & 1 & 1 & 2 & 0 & 0 & 35 \\
\hline 34.VIRI & 1 & 0 & 250 & 1 & 1 & 0 & 0 & 0 & 0 & 1 & 1 & 2 & 1 & 2 & 0 & 0 & 85 \\
\hline 35.VIRL & 1 & 0 & 210 & 1 & 1 & 0 & 0 & 0 & 0 & 1 & 1 & 2 & 1 & 1 & 1 & 30 & 80 \\
\hline
\end{tabular}


Epidermis foliar de Trisetum (Poaceae): FinOT, V.
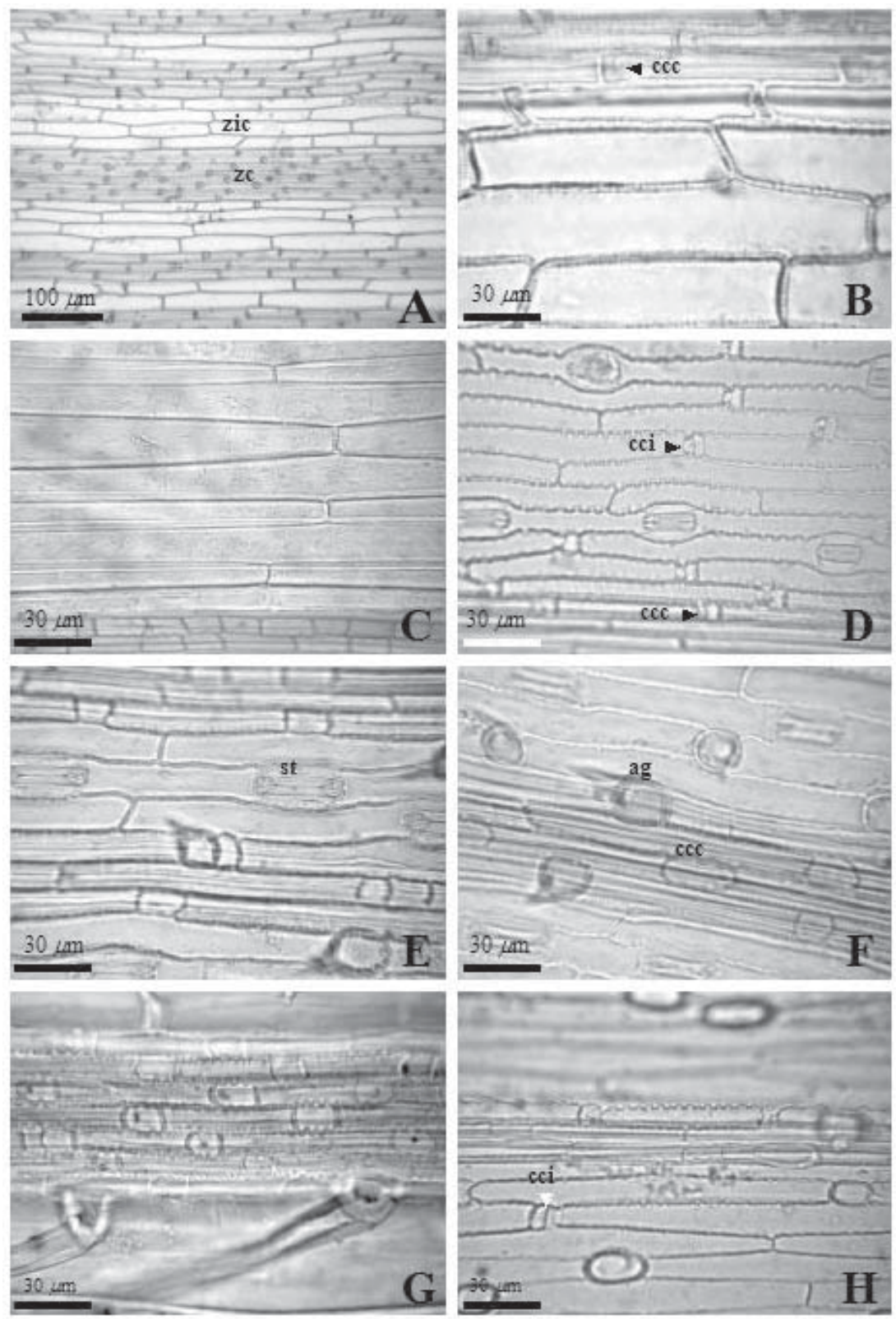

Figura 1. Epidermis abaxial (M.O). A-B. Deschampsia brasiliensis (Chase 8304, 10x). A. Vista general (10x). B. D. brasiliensis (Chase 8304, 40x) Detalle (40x). C. Helictotrichon bulbosum (Finot \& Baeza 2066, 40x). D. Trisetum angustum (Steyermark 35525, 40x). E. T. barbinode (Finot \& Baeza 2073, zona intercostal, 40x). F. T. barbinode (Finot \& Baeza 2073, zona costal, (40x). G. T. caudulatum (Pfister s.n., 40x). H. T. curvisetum (Peterson et al. 16764, 40x). ccc $=$ células cortas costales; cci $=$ células cortas intercostales .

Figure 1. Abaxial epidermis (L.M.). A. Deschampsia brasiliensis (Chase 8304, 10x). B. D. brasiliensis (Chase 8304, 40x). C. Helictotrichon bulbosum (Finot \& Baeza 2066, 40x). D. Trisetum angustum (Steyermark 35525, 40x). E. T. barbinode (Finot \& Baeza 2073, intercostal zone, 40x). F. T. barbinode (Finot \& Baeza 2073, costal zone, 40x). G. $T$. caudulatum (Pfister s.n., 40x). H. T. curvisetum (Peterson et al. 16764, 40x). ccc $=$ costal short cells; $c$ ci $=$ intercostal short cells. 

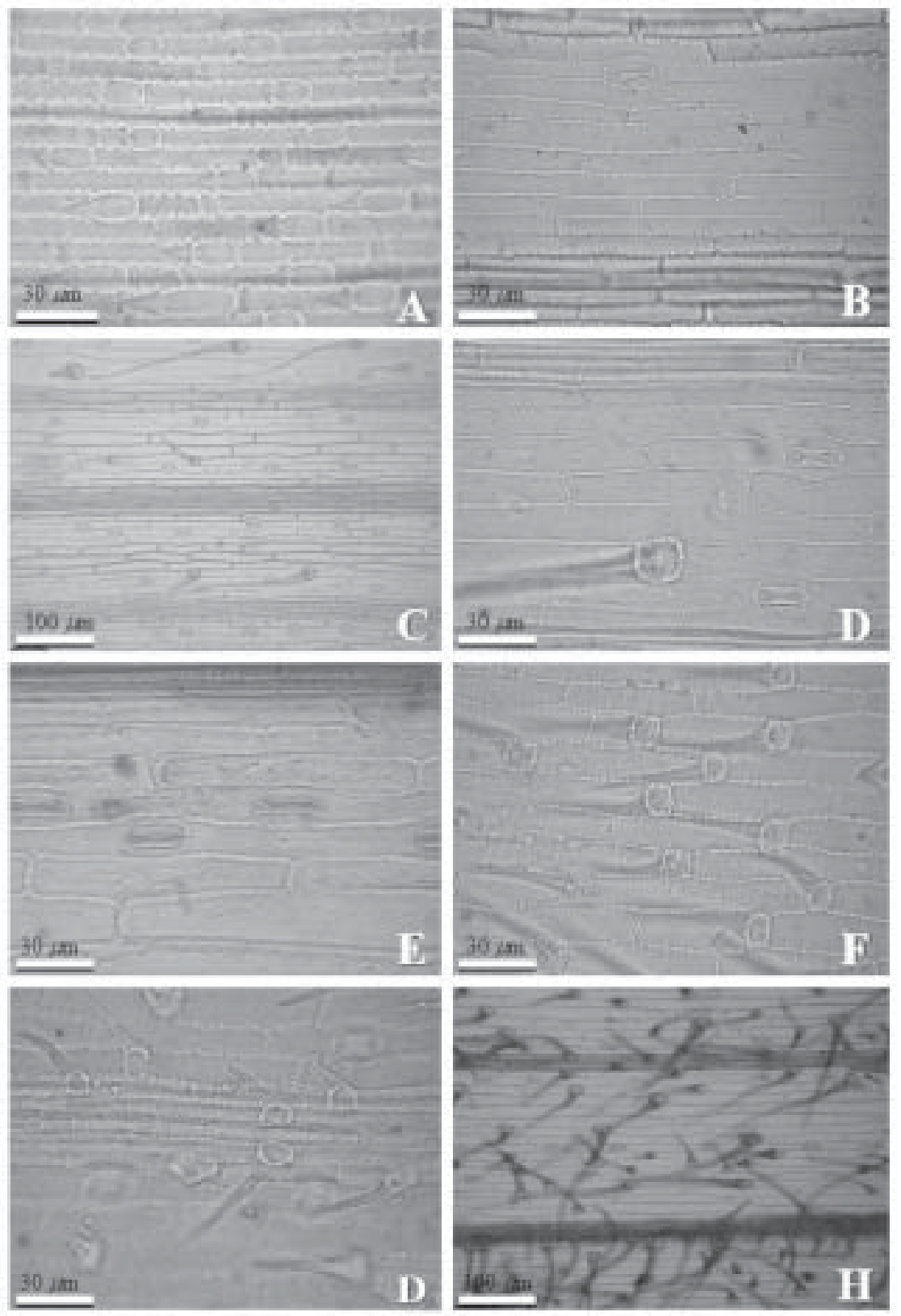

FigURA 2. Epidermis abaxial en Trisetum (M.O.). A. T. filifolium (Hitchcock 7682), mostrando epidermis uniforme, con zonas costales e intercostales no diferenciadas. B. T. flavescens (Leckenby 19a). C-D. T. ligulatum (Peterson \& Blackburn 13778). C. Aspecto general mostrando zonas costales (zc) e intercostales (zic). D. Detalle mostrando estomas (st) y macropelos (mp). E. T. longiglume (Arroyo et al. 94454), zona intercostal. F-G. T. mattheii (Marticorena et al. 86). F. Zona intercostal. G. Zona costal. H. T. nancaguense (Villarroel \& Weldt 151).

Figure 2. Abaxial epidermis in Trisetum (L.M.). A. T. filifolium (Hitchcock 7682), showing uniform epidermis with indistinct costal and intercostal zones. B. T. flavescens (Leckenby 19a). C-D. T. ligulatum (Peterson \& Blackburn 13778). C. General appearance showing costal (zc) and intercostal zones (zic). D. Detail showing stomata (st) and macrohairs (mp). E. T. longiglume (Arroyo et al. 94454), intercostal zone. F-G. T. mattheii (Marticorena et al. 86). F. Intercostal zone. G. Costal zone. H. T. nancaguense (Villarroel \& Weldt 151). 
Epidermis foliar de Trisetum (Poaceae): Finot, V.
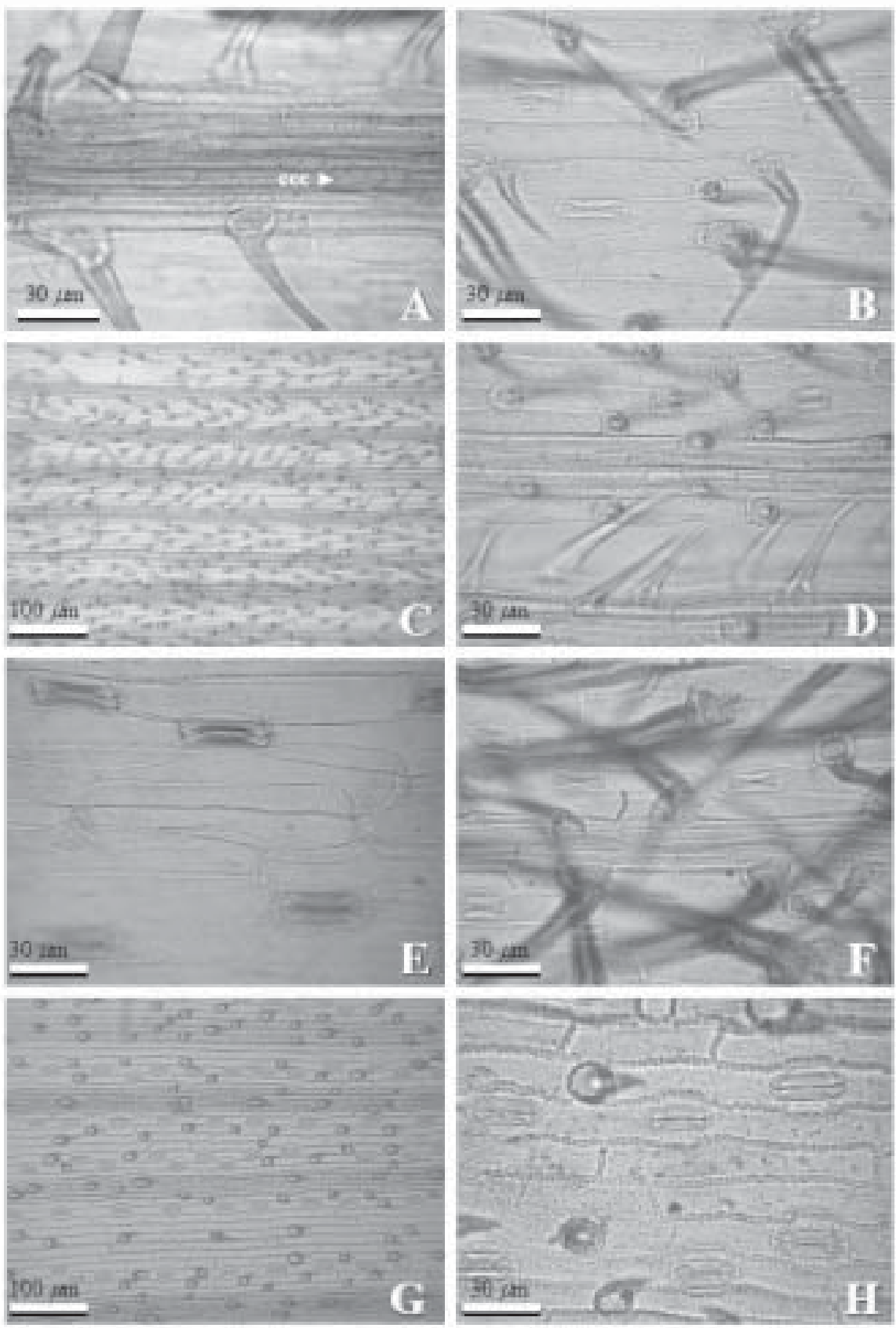

Figura 3. Epidermis abaxial en Trisetum (M.O.). A-B. T. nancaguense (Villarroel \& Weldt 151). A. Zona costal. B. Zona intercostal. C-D. T. oreophilum var. oreophilum (Peterson et al. 8866). E. T. orthochaetum (Chase 5129). F. T. phleoides (Pico s.n.). G-H. T. preslei (Gunckel 20297). ccc = células cortas intercostales.

Figure 3. Abaxial epidermis in Trisetum (L.M.). A-B. T. nancaguense (Villarroel \& Weldt 151). A. Costal zone. B. Intercostal zone. C-D. T. oreophilum var. oreophilum (Peterson et al. 8866). E. T. orthochaetum (Chase 5129). F. T. phleoides (Pico s.n.). G-H. T. preslei (Gunckel 20297). ccc = células cortas intercostales. 

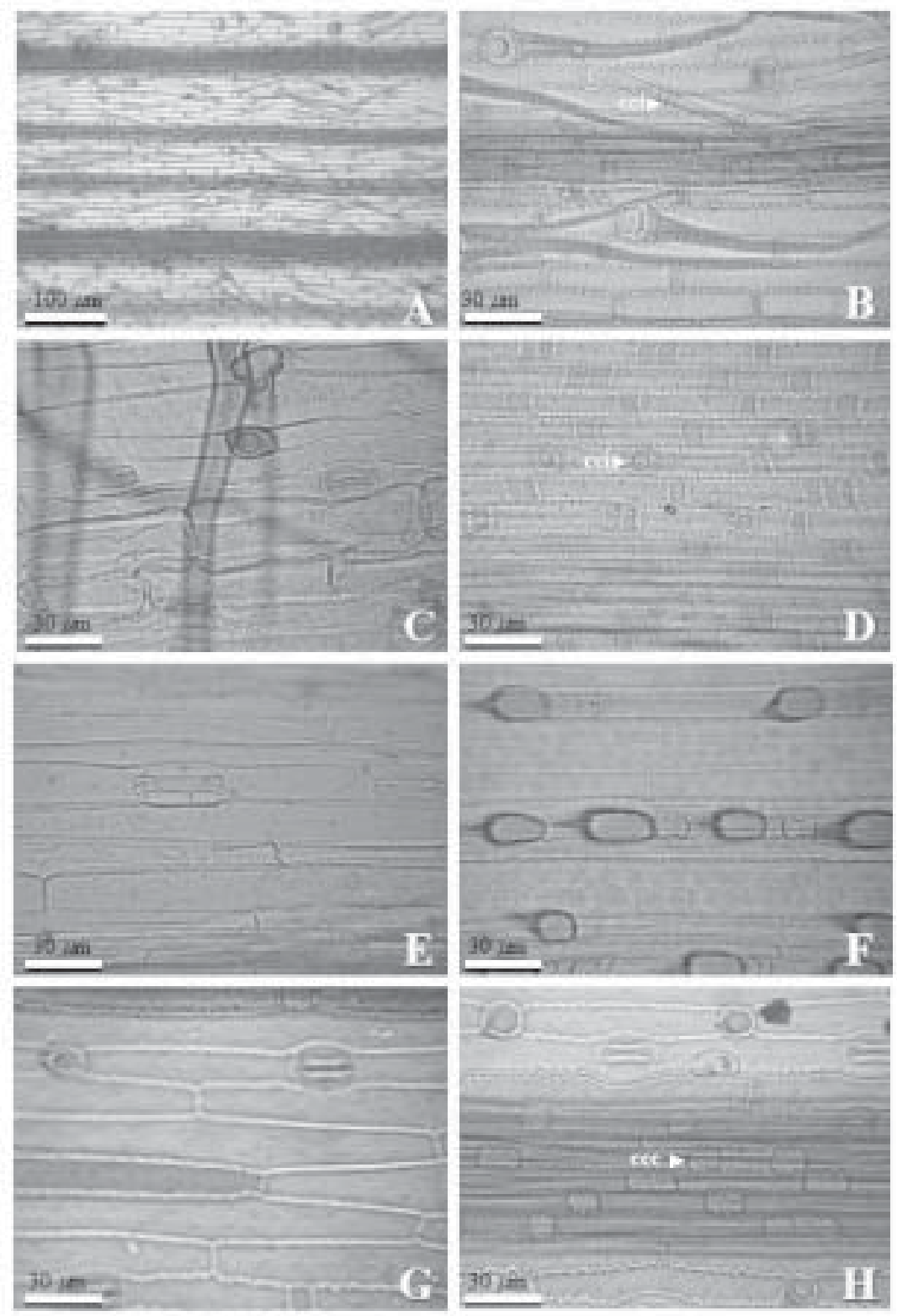

Figura 4. Epidermis abaxial en Trisetum (M.O.). A-B. T. pringlei (Pohl \& Davidse 10694). A. Vista general mostrando zonas costales (zc) e intercostales (zic). B. Detalle mostrando células cortas costales (ccc), células cortas intercostales (cci) y macropelos (mp). C. T. projectum (Swallen 853). D. T. rosei (Beaman 1729a), mostrando zonas costal (zc) e intercostal (zic) similares. E. T. sibiricum (Hultén s.n.), zona intercostal. F. T. spellenbergii (Peterson \& Annable 12509), mostrando zonas costal (zc) e intercostal (zic). G-H. T. spicatum (Finot \& Baeza 2072). G. Zona intercostal. H. Zona costal.

Figura 4. Abaxial epidermis in Trisetum (L.M.). A-B. T. pringlei (Pohl \& Davidse 10694). A. General appearance showing costal (zc) and intercostal zones (zic). B. Detail showing costal short cells (ccc), intercostal short cells (cci) and macrohairs (mp). C. T. projectum (Swallen 853). D. T. rosei (Beaman 1729a), showing similiar costal costal (zc) and intercostal zones (zic). E. T. sibiricum (Hultén s.n.), intercostal zone. F. T. spellenbergii (Peterson \& Annable 12509), showing costal (zc) and intercostal zones (zic). G-H. T. spicatum (Finot \& Baeza 2072). G. Intercostal zone. H. Costal zone. 
Epidermis foliar de Trisetum (Poaceae): FinOT, V.
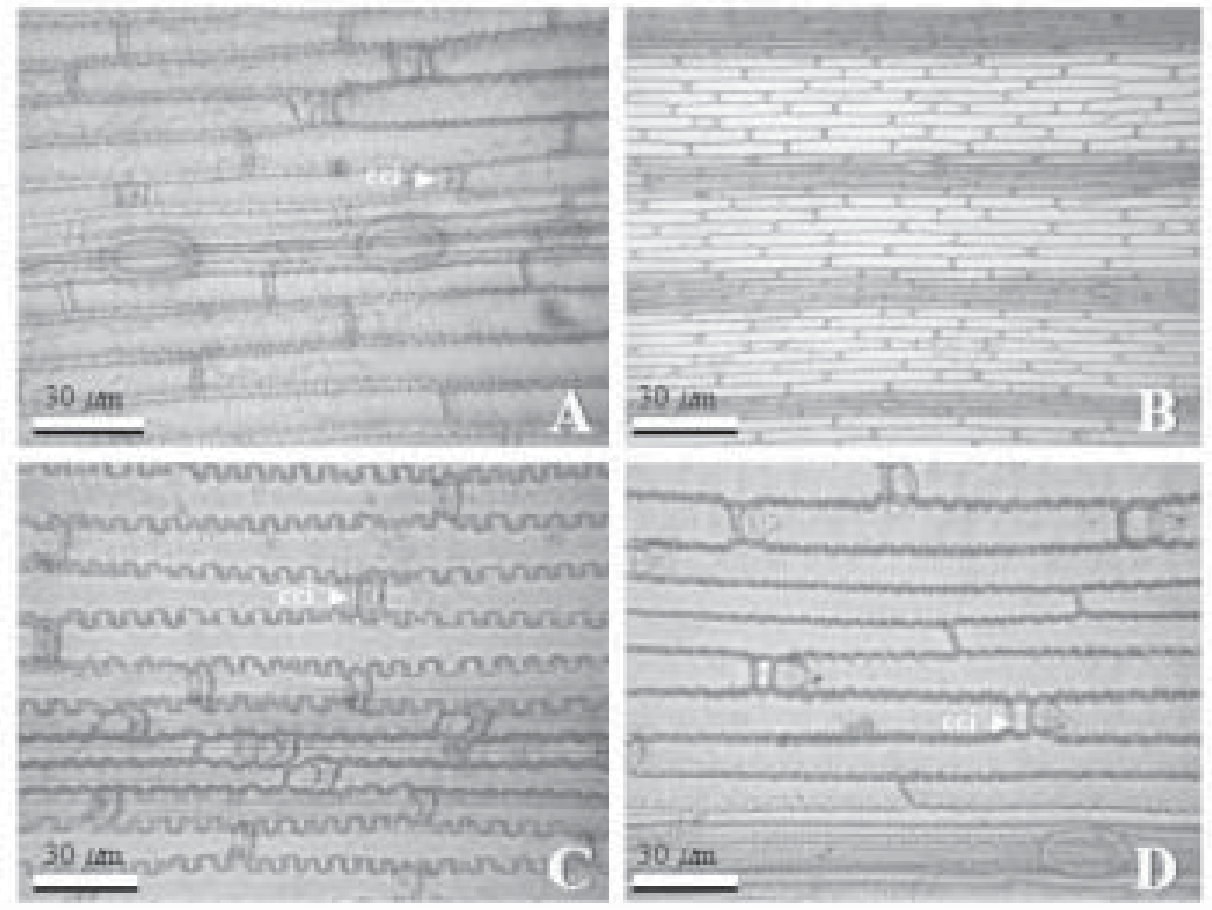

Figura 5. Epidermis abaxial en Trisetum (M.O.). A. T. tonduzii (Pohl \& Davidse 10618). B-C. T. viride (Peterson et al. 13432). B. Aspecto general. C. Detalle mostrando células cortas costales (ccc) y células cortas intercostales (cci) similares. D. T. virletii (Iltis \& Iltis 1671-a), mostrando células cortas intercostales (cci).

Figura 5. Abaxial epidermis in Trisetum (M.O.). A. T. tonduzii (Pohl \& Davidse 10618). B-C. T. viride (Peterson et al. 13432). B. General appearance. C. Detail showing costal short cells (ccc) and intercostal short cells (cci) similar. D. T. virletii (Iltis \& Iltis 1671-a), showing intercostal short cells (cci). 

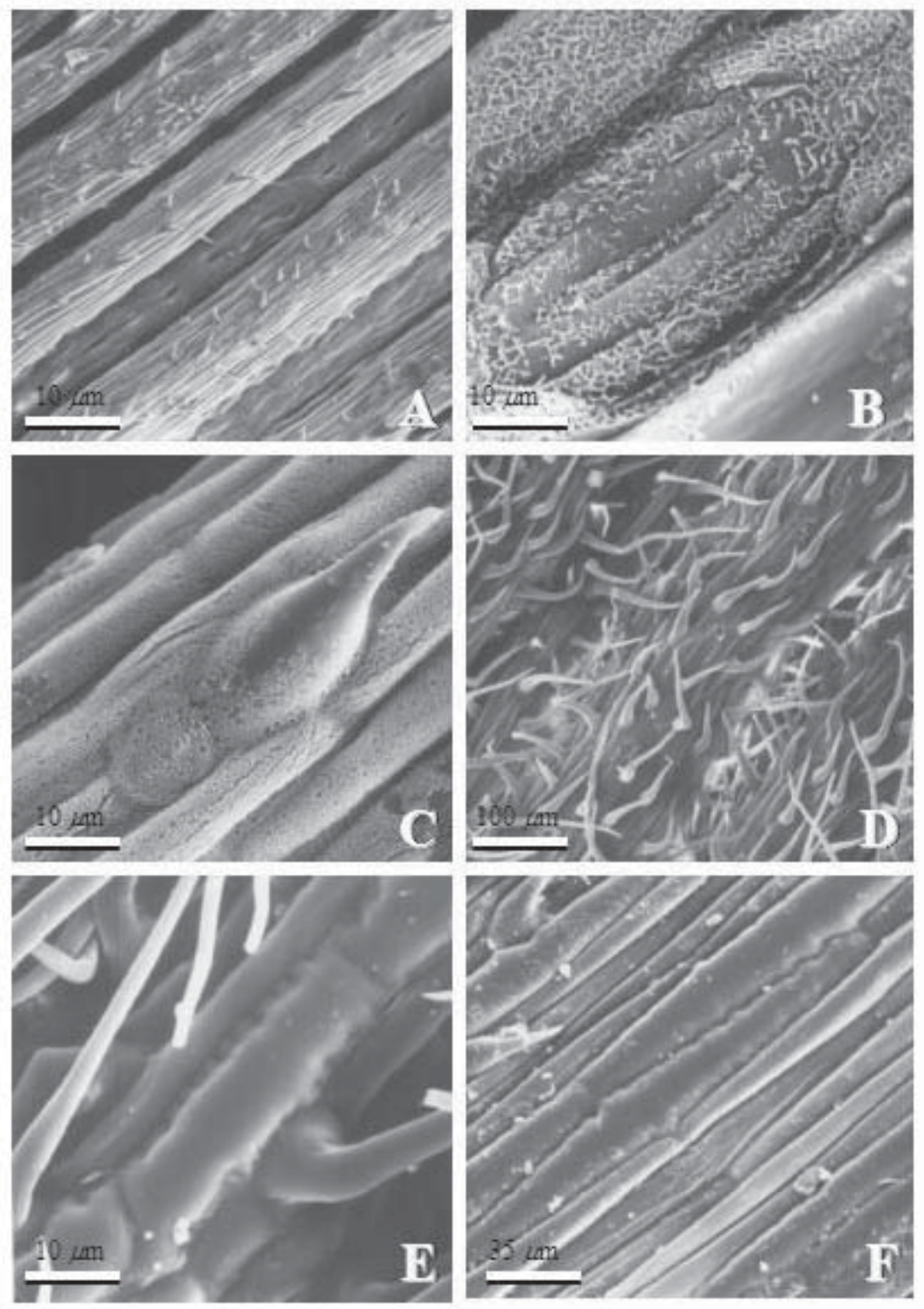

Figura 6. Epidermis adaxial en Trisetum (M.E.B.). A-C. T. barbinode (Garaventa 4681). A. Aspecto general. B. Detalle mostrando un estoma. C. Detalle mostrando aguijón y célula corta. D-E. T. phleoides (Pisano 5198). F. T. spicatum (Schwabe 69).

Figure 6. Adaxial epidermis in Trisetum (S.E.M.). A-C. T. barbinode (Garaventa 4681). A. General appearance. B. Detail showing a stoma. C. Detail showing a prickle hair and short cell. D-E. T. phleoides (Pisano 5198). F. T. spicatum (Schwabe 69). 
Epidermis foliar de Trisetum (Poaceae): FinOT, V.

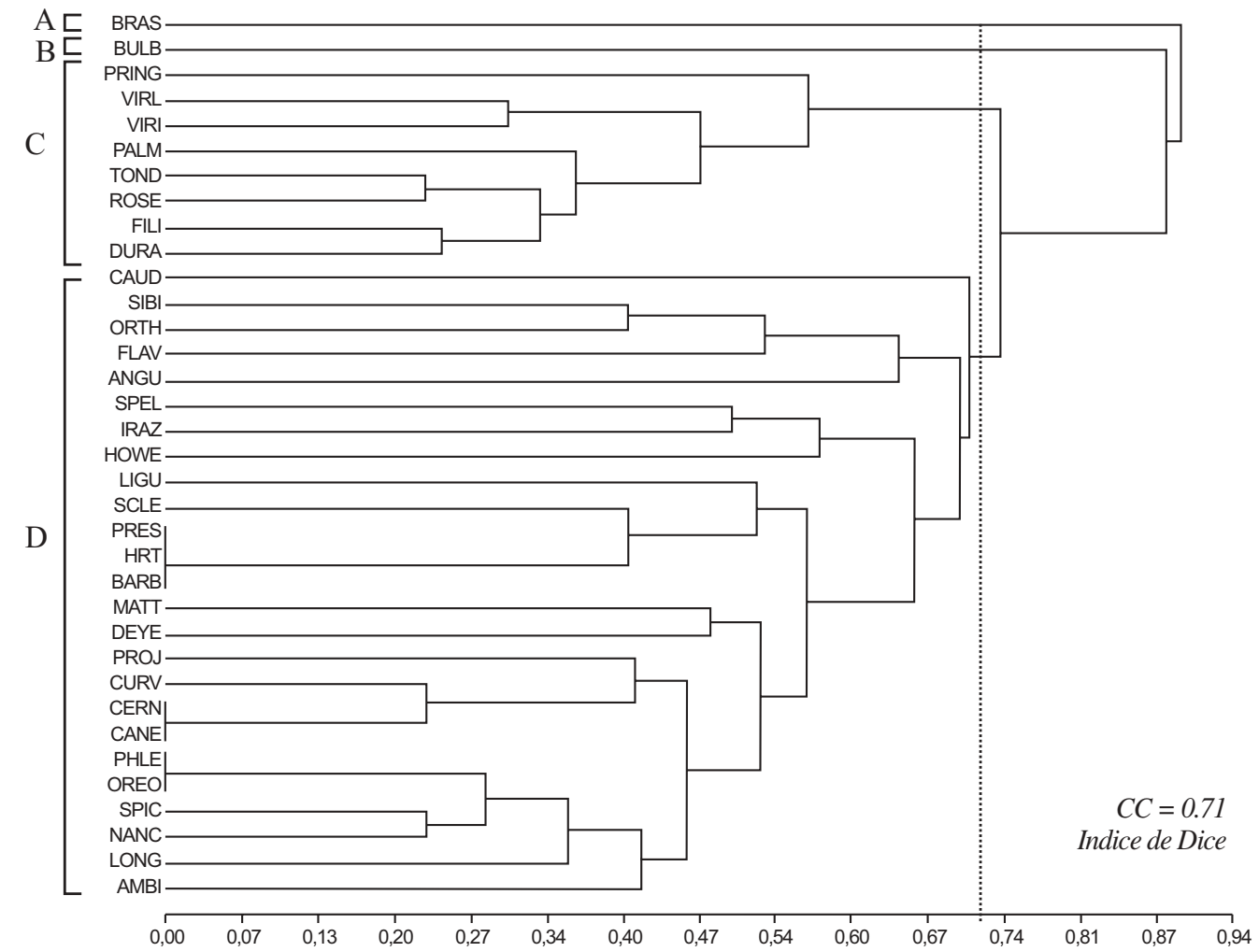

FIGURA 7. Fenograma de ligamiento promedio (UPGMA) para de 35 taxa de Trisetum, basado en 17 caracteres de la epidermis abaxial, utilizando el índice de distancia de Dice. CC = Coeficiente de Correlación cofenética. A, B, C y D: grupos reconocidos a $\mathrm{D}=0.70$. Los acrónimos de las especies se señalan en la Tabla $\mathrm{I}$.

FIGURE 7. UPGMA phenogram of 35 taxa of Trisetum based on 17 characters of the abaxial epidermis. $\mathrm{CC}=$ Cophenetic correlation. A, B, C and D: recognized groups at $\mathrm{D}=0.70$. Species acronyms are indicated in Table I. 


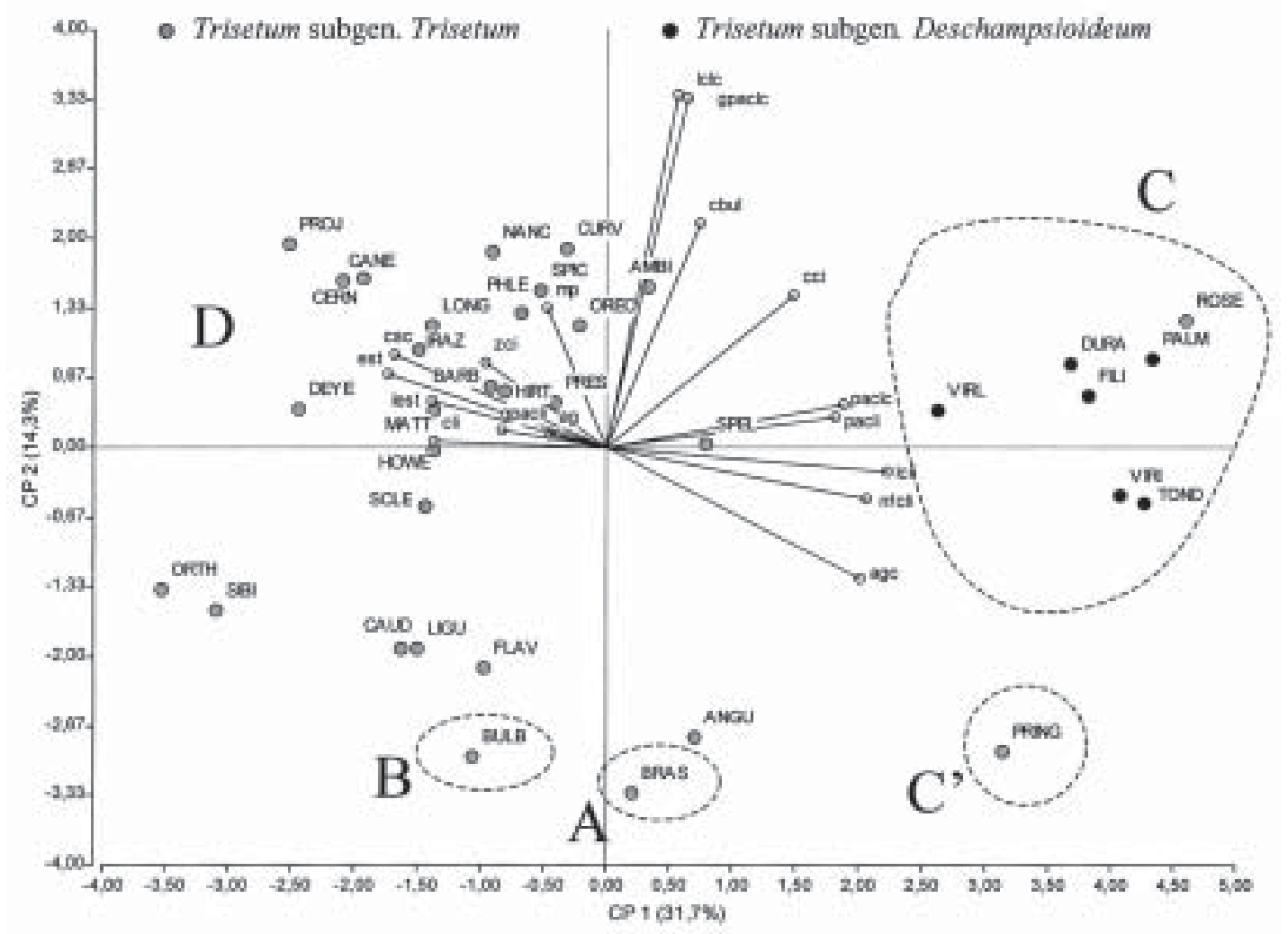

Figura 8. Análisis de componentes principales (APC). Distribución de los taxa estudiados en los dos primeros ejes de APC. Las letras A, B, C y D señalan los grupos de especies encontrados previamente mediante el análisis de agrupamientos. C' muestra a T. pringlei separado del grupo C por el APC. El primer componente principal explica un $31.7 \%$ de la varianza total; el segundo componente explica un $14.3 \%$ de la varianza total. Los acrónimos se señalan en la Tabla I.

FIGURE 8. Principal component analysis (PCA). Distribution of the studied taxa on the two first axes of the PCA. A, B, $\mathrm{C}$ and $\mathrm{D}$ show the groups of species previously found by the cluster analysis. $\mathrm{C}^{\prime}$ shows $T$. pringlei separated from group $\mathrm{C}$ by the PCA. The first principal component accounts for $31.7 \%$ of the total variance; the second principal component accounts for $14.3 \%$ of the total variance. Species acronyms are indicated in Table I. 


\section{AGRADECIMIENTOS}

Trabajo financiado por el Proyecto DIUC 204.121.009-1.0 y 205.111.047-1.0. Deseo expresar mi agradecimiento a los curadores de los herbarios BA, BAA, BAF, CONC, CR, F, P, PR, QCA, S, SI, SGO, US, USL y al Prof. Otto Zoellner que me permitieron el acceso o me enviaron en préstamo sus colecciones. Al personal del Laboratorio de Microscopía Electrónica de la Universidad de Concepción, su valiosa asistencia en la preparación y observación de las muestras. A los Prof. Clodomiro Marticorena, Oscar Matthei, Fernando Zuloaga, Lohengrin Cavieres, Marcelo Baeza, Roberto Rodríguez, María Negritto y Alicia Marticorena sus valiosas sugerencias y ayuda durante toda la investigación.

\section{BIBLIOGRAFIA}

Acedo, C. \& F. Llamas. 2001. Variation of micromorphological characters of lemma and palea of genus Bromus (Poaceae). Annali Botanici Fennici 38: 1-14.

Aiken, S.G. \& L.P. Lefkovitch. 1984. The taxonomic value of using epidermal characteristics on the Canadian Rough Fescue Complex (Festuca altaica, F. campestris, F. halii, "F. scabrella"). Canadian Journal of Botany 62: 1864-1870.

ArRiaga, M.O. 1983. Anatomía foliar de las especies de Stipa del subgénero Pappostipa (StipeaePoaceae) de Argentina. Revista del Museo Argentino de Ciencias Naturales 6: 89-141.

BAEZA, C.M. 1997. Anatomía foliar y epidermis abaxial de las especies americanas de Danthonia DC. y Rytidosperma Steud. (Poaceae). Gayana Botánica. 54: 61-88.

BARKWORTH, M.E. 1981. Foliar epidermes and taxonomy of North American Stipeae (Gramineae). Systematic Botany 6: 136-152.

BAUM, B.R. 1971. Organophyletic trends in several micromorphological floral traits in the hexaploid cultivated oats (Avena). Evolution 25: 235-241.

Chaffer, N.J. 1983. Epidermal structure in the ligule of rice (Oryza sativa). Annals of Botany 52: 13-21.

Chaffey, N.J. 1984. Epidermal structure in the ligules of four species of the genus Poa L. (Poaceae). Botanical Journal of the Linnean Society 89: 341354.

Chaffey, N.J. 1985. Structure and function in the grass ligule: optical and electron microscopy of the membranous ligule of Lolium temulentum L. Annals of Botany 55: 65-75.

Chaffey, N.J. 1994. Structure and function of the membranous grass ligule: a comparative study.
Botanical Journal of the Linnean Society 116: 53-69.

Chrtek, J. 1965. Bemerkungen zur Gliederung der Gattung Trisetum Pers. Botaniska Notiser 118: 210-224.

Chrtek, J. and V. Jirásek. 1963. On the taxonomy of the genus Trisetum Pers. Webbia 17: 569-580.

Clark, C.A. \& F.W. Gould. 1975. Some epidermal characteristics of paleas of Dichantelium, Panicum and Echinochloa. American Journal of Botany 62: 743-748.

Conert, H.J. 1987. Poaceae. In. Hegi, G. (ed.) Ill. Fl. Mitt.-Eur. 3 Aufl. 1(3), Lief. 4: 241-320.

Dávila, P. \& L.G. Clark. 1990. Scanning electron microscopy survey of leaf epidermis of Sorghastrum (Poaceae: Andropogoneae). American Journal of Botany 77: 499-511.

Ellis, R.P. 1976. A procedure for standardizing comparative leaf anatomy in the Poaceae. I. The leaf blade as viewed in transverse section. Bothalia 12(1): 65-109.

Ellis, R.P. 1979. A procedure for standardizing comparative leaf anatomy in the Poaceae. II. The epidermis as seen in surface view. Bothalia 12(4): 641-671.

Finot, V.L., C.M. Baeza \& O. Matthei. 2006. Micromorfología de la epidermis de la lemma de Trisetum y géneros afines (Poaceae: Pooideae). Darwiniana 44: 32-57.

Finot, V.L., P.M. Peterson, R.J. Soreng \& F. Zuloaga. 2004. A revision of Trisetum, Peyritschia and Sphenopholis (Poaceae: Pooideae: Aveninae) in Mexico and Central America. Annals of the Missouri Botanical Garden 91 : 1-30.

Finot, V.L., P.M. Peterson, R.J. Soreng \& F.O. Zuloaga. 2005a. A revision of Trisetum and Graphephorum (Poaceae: Pooideae: Aveninae) in North America North of Mexico. Sida 21(3): 1419-1453.

Finot, V.L., P.M. Peterson, F.O. Zuloaga, R.J. Soreng \& O. Matthei. 2005b. A revision of Trisetum (Poaceae : Pooideae : Aveninae) in South America. Annals of the Missouri Botanical Garden 93: 533-568.

Gamisans, J. 1971. Contributions à l'étude de la flore de la Corse. II. Candollea 26: 309-358.

HernándeZ-Torres, I. \& E.M. Engleman. 1995. Anatomía de la lámina foliar del género Trisetum (Gramineae: Pooideae) en México. Acta Botánica Mexicana 31: 39-50.

HernándeZ-TorRes, I. \& S.D. Koch. 1988. Anatomía de la lámina foliar de Trisetum, Deschampsia y Peyritschia y sus implicaciones taxonómicas. Agrociencia 71: 61-69.

Herrera, Y. \& W.F. Grant. 1994. Anatomy of the Muhlenbergia montana complex (Poaceae). American Journal of Botany 81: 1038-1044.

Infostat. 2004. InfoStat versión 2004. Grupo InfoStat, FCA, Universidad Nacional de Córdoba, Argentina. 
Metcalfe, C.R. 1960. Anatomy of the Monocotyledons. I. Gramineae. Oxford University Press, London.

Matthei, O. 1982. El género Festuca (Poaceae) en Chile. Gayana Botánica 37: 1-64.

Paunero, E. 1950. Las especies españolas del género Trisetaria Forsk. Anales del Jardín Botánico de Madrid 9: 503-582.

Peterson, P.M., C.R. Annable \& V.R. Franceschi. 1989. Comparative leaf anatomy of the anual Muhlenbergia (Poaceae). Nordic Journal of Botany $8: 575-583$.

Prat, H. 1932. L' épiderme des Graminées: étude anatomique et systématique. Annales des Sciences Naturelles, Botanique, sér. 10, 14: 117-324.

Prat, H. 1936. La systématique des graminées. Annales des Sciences Naturelles, Botanique, sér. 10, 18: 165-258.

Prat, H. 1948. General features of the epidermis in Zea mays. Annals of the Missouri Botanical Garden 35: 341-351.

Prat, H. 1961. Emploi des caractères épidermiques dans la classification des graminées. Recent Advances in Botany 1: 99-102.

Stewart, D.R.M. 1965. The epidermal characters of grasses, with special reference to East African plains species. Botanische Jahrbürcher 84: 63-116.

TAteoka, T., Inowe, S. \& K. Kawano. 1959. Notes on some grasses IX: Systematic significance of bicellular microhairs of leaf epidermis. Botanical Gazette 121: 80-91.

Terrel, E.E. \& W. P. Wergin. 1981. Epidermal features and silica deposition in lemmas and awns of Zizania (Gramineae). American Journal of Botany 68: 697-707.

Terrel, E.E., W.P. Wergin \& S.A. Renvoize. 1983. Epidermal features of spikelets in Leersia (Poaceae). Bulletin of the Torrey Botanical Club 110: 423-434.

Thomasson, J.R. 1978. Epidermal patterns of the lemma in some fossil and living grasses and their phylogenetic significance. Science 199: 975-977.

Thomasson, J.R. 1986. Lemma epidermal features in the North American species of Melica and selected species of Briza, Catabrosa, Glyceria, Neostaphia, Pleuropogon and Schizachne (Gramineae). Systematic Botany 11:253-262.

Zuloaga, F.O., Morrone, O. \& E. Judziewicz. 1993. Endemic herbaceous bamboo genera of Cuba (Poaceae: Bambusoideae: Olyreae). Annals of the Missouri Botanical Garden 80: 846-861.

Recibido: 10.04.06

Aceptado: 13.07.06 